\title{
Expelliarmus Versus Dëbimus: Harry Potter's Magical World in Albanian Language
}

\author{
Aida ALLA, Ph.D Cand.
}

AAB University

\begin{abstract}
The Harry Potter saga, written by the British writer J.K. Rowling, has gained accredited attention worldwide, thus being translated in more than 64 languages, including Albanian, and selling more than 450 million copies. The saga combines a variety of genres, fantasy being the most predominant one. The magical elements in the fantasy genre are portrayed with a delicate choice of words on the part of the writer, encompassing neologisms, Latinisms and French-rooted words which name the objects, events, behaviors of the imaginary world, to mention a few. The present paper aims to investigate how these features are rendered into Albanian so that the effect of the source text is preserved in the target text. The first three Harry Potter novels will constitute the corpus of our study. Such an investigation will be possible through the conduction of a comparative analysis illustrated with examples which will theoretically be based on the translation procedures and strategies offered by scholars in the discipline of translation studies. Two approaches will be utilized as far as analysis is concerned: following Axiela's division of culture specific items in two groups - common expressions and proper nouns - Finally, conclusions will be drawn regarding the transfer of the similar effect of the magic-related terms from the source text to the target text.
\end{abstract}

Keywords: magic-related terms, translation procedures, neologisms, Latinisms, similar effect

\section{Introduction}

Before we start to elaborate on the challenges of children's literature translation as well as the comparative analysis, it is essential to refer to some peculiarities and characteristics of children's literature as such. The vast array of children's literature has to be divided according to some format (picture books, chapter books, illustrated books) as well as by topics or issues (death, race, family matters, friendship, etc.). Thus, it is somehow difficult to give a single definitons about the children's literature since it can be perceived based on genra, text length, children's age, purpuse, etc. Additinally, it might change in the course of time, place and culture. However, for the pupruse of this study, we will concentrate only on those characteristics that direclty affect translation.

One of the characteristics of children's literature is its ambivalence due to the fact of its dual readership. To Rurvin and Orlati, ambivalent texts are those "written for and received by both adults and children at various textual levels of both production and reception" (2006: 159).

Asymmetry is another feature of children's literature which entails the relationship between the writers who are adults and the readers who are children. When the partners in communication are not equal, communication structures are asymmetric. Children's literature differs from adults literature in that the authors of children's books and their audience have a different level of knowledge and experience. It is adults who decide on the literary form and it is they who decide what to publish and what to sell without giving the children a chance to decide for themselves.

Onother important characteristic of children's literature seen from the pedodical viewpoint is to educate the child reader. As Puurtinen points out, adults expect children's literature to help in the development of the child's linguistic skills. Therefore, there might be a stronger tendency for aothors and translators of children's literature to normalise the texts by grammaticising them, in order to avoid the readership learning faulty grammar from the books. (Puurtinen: 1998). 


\section{A theoretical overview of Children's Literature Translation}

The study of children's literature is a well established discipline and a lot of scholars are giving their contribution despite the wrong conception that children's literature is of less importance and less sophisticated than adults' literature. On the other hand, translation studies of children's literature are embryonic and only in the last two decades are theorists elaborating on the translation strategies with a focus on children as a target group and their reading competences and demands. Attempts have been made to differentiate between characteristics of children's literature translation and adults' literature translation. Generally speaking, there are two main trends of translation procedure which apply to both children and adults' literature: source oriented translation and target oriented translation. The first approach advocates the preservation of the source language and cultural characteristics (being faithful to the form and meaning) whereas the latter favors the "merging" of source text into the target language culture, bringing it closer to the readership.

However, when it comes to children's literature, this dilemma becomes more problematic when the readership is dual. Quoting Metcalf: "More children's books than ever before address a dual audience of children and adults, which on the other hand comes with a dual challenge for the translator, who now has to address both audiences in the translated literature" (2003: 323). To preserve multiple levels in the text, the conventional one to be simply realized by the child reader; the other one only understandable to adults, is one of the biggest challenges for translators of children's literature. (Frimmelova 2010: 35) The Harry Potter saga is a very good illustration of an ambivalent text. Hundreds of pages and a seven-book compilation cannot be appealing to teenagers only, not to mention the linguistic complexities and layers it encompasses due to the author's sophisticated style of writing.

Additionally, during the decision-making process, the translator of children's literature should consider the specifications of the target language readership, their limited knowledge of the world as well as the ideologies which govern the target language and culture. As Riitta Oittinen puts it "while translating as rewriting for target-language audiences - we always need to ask the crucial question: 'For whom?' Hence, while writing children's books is writing for children, translating children's literature is translating for children" $(2003,128)$.

Instead of aiming at an adequate translation, the translator should aim at an acceptable translation considering the fact that children's reading abilities are not as advanced as the adults' and their knowledge of the world is limited. Ztolze is another scholar who tackled this issue. He stated that "It is the task of the translator to decide how she/he will compensate for the children's lack of background knowledge without oversimplifying the original and forcing children into simple texts that have lost any feature of difficulty, foreignness, challenge and difficulty". (2003: 209)

In the late 1980s, Klingberg, in his Children's Fiction in the Hands of the Translators, criticized what he perceived as the most common way to translate books for children. In his view, the main aim of this activity should be that of enriching the reader's knowledge and understanding of foreign cultures. Yet, most translators' interventions on the source texts - what he categorizes as 'cultural context adaptations', 'purifications' 'modernizations', 'abridgements' and 'serious mistranslations' - hinder that aim. Klingberg suggested that translation strategies which tend to preserve the foreign spirit of the originals should be preferred, so that the child-reader can get acquainted with the country and the culture from where those books come.

Zohan Shavit is another scholar who has given important contribution to the translation of children's literature. According to her, unlike contemporary translators of the adults' books, the translator of children's literature can permit himself great liberties regarding the text as a result of the peripheral position of the children's literature within the polysystem. That is, the translator is permitted to manipulate the text in various ways by changing, enlarging or abridging it or by deleting or adding to it. (1986: 111) "In viewing translation as part of a transfer process, it must be stressed that the subject at stake is not just translations of texts from one language to another, but also the translations of texts from one system to another -for example, translations from the adult system into the children's." (Shavit 1986: 111)

\section{A theoretical overview of the Cultural References}

Before we embark on the comparative analysis of culture references in the Harry Potter series, it is important to set some theoretical ground on what such references are. Peter Newmark and Gote Klingmerg and Javier Franco Axela are among distinguished scholars who have elaborated on this term. 
Newmark distinguishes between cultural language and universal language. He states "I define culture as the way of life and its manifestations that are peculiar to a community that uses a particular language as its means of expression. More specifically, I distinguish 'cultural' from 'universal1 and 'personal1 language. 'Die, 'live, 'star', 'swim' and even almost virtually ubiquitous artefacts like 'mirror' and "table" are universals - usually there is no translation problem there. 'Monsoon', 'steppe', 'dacha', 'tagliatelle' are cultural words - there will be a translation problem unless there is cultural overlap between the source and the target language (and its readership)." ( 1988 -94). In more details, he classifies them in five categories: (ibid: 95)

(1) Ecology Flora, fauna, winds, plains, hills

(2) Material culture (artefacts) (a) Food (c) Houses and towns (d) Transport

(3) Social culture - work and leisure

(4) Organisations, customs, activities, procedures, concepts (a) Political and administrative (b) Religious(c) Artistic

(5) Gestures and habits

Gote Klingmerg has also provided a scheme for cultural words which covers the following categories: literary references, foreign languages on the source text, references to mythology and popular belief, historical, religious and political background, building and home furnishings, food, customs and practices, play and games, flora and fauna, personal names, titles, names of domestic animals, names of objects, geographical names.

Such terms are labeled as "culture-specific items" (CSIs) by Franco Jafier Aixela. Even though Aixela avoids offering an exact definition of CSIs, claiming that they are recognized through a "sort of collective intuition", he stresses the fact that "In translation, a CSI does not exist of itself, but as a result of a conflict arising from the linguistically represented reference in a source text which, when transferred to a target language, poses a translation problem due to the nonexistence or to the different value (when determined by ideology, usage, frequency, etc.) of the given item in the target language culture. ( 1996: 57) Aixela distinguishes two types of cultural items in a given text. The first category includes proper nouns and the other one includes "common expressions" such as: the world of objects, institutions, habits and opinions restricted to each culture. All those "exotic" terms can impose difficulties to translators who are faced with the challenge of making a decision between preservation of such exotizm or domesticating them in the target language culture. This classification will guide the comparative analysis of this study.

\section{Magic-related words as cultural references in the Harry Potter series}

The Harry Potter books, being predominately part of the fantasy genre, are abundant in alien and coined terms which fit with the magical world that Harry Potter lives in. Nancy K. Jentsch in her study titled "Harry Potter and the Tower of Babel: Translating the Magic" focuses on the Harry Potter translators' problems and according to her, the newly coined words present unusual difficulties to the translator. (Jentsch 2002: 285) On the other hand, there is a parallel world aside the magical one, in which non-magicians live. This dichotomy is portrayed not only by the creation of two different settings the Hogwarts School of Magicians and the Privet Drive respectively - but also through the events, activities, magical creatures, behaviors, etc. Jentsch stated that "This juxtaposition of magical and Muggle worlds is integral to the original text and must be a serious consideration to its translators. The translator thus has to decide not only how to translate, but when to translate and when to leave words in the original". (Jentsch 2002: 285

Both Aixela's categories of CSIs - proper nouns and common expressions - are applicable in the Harry Potter saga. In children's fantasy literature proper nouns have a crucial role in portraying the character's personality, conveying a message, creating comic effects, showing mysteriousness, having esthetic effect and providing hints to the reader on what to expect from a certain character. Tymoczko claims that proper names also indicate "racial, ethnic, national, and religious identity". $(1999,223)$ Therefore, she calls proper names "dense signifiers" and explains that they are "the most problematic to translate, in part because their significance is often culturally specific and dependent on cultural paradigms". Thus, proper names may indicate a certain meaning, historical aspect, geographical area or culture. 
As for the second category of CSIs, namely "common expressions", they can be observed in the words describing events, gatherings, games, behaviors, etc. The scope of this study will cover the both categories of SCls and a comparative analysis will be conducted with the aim of revealing whether these culturally loaded words have been transferred with the "similar effect" in mind.

\section{Critical analysis of magic-related words as cultural references}

As we mentioned above, a distinctive feature of J.K. Rowling writing style is the usage of neologisms, borrowings and Latin and French words. A comparative analysis will be presented with the aim of noticing the transference of similar effect in the target language.

Translation of Latin-based spells and charms

\begin{tabular}{|l|l|}
\hline Source Text & Target Text \\
\hline Petrificus Totalus & Nguros Gjithus \\
\hline Lumos: & Dritum \\
\hline Aparecium: & Dukus \\
\hline Expelliarmus & Dëbimus \\
\hline Nox/Noxtic & Terrus \\
\hline Confunfus & Ngatërrimus \\
\hline Expecto Patronum & Pres Patronumin (HP3) \\
\hline Locomotor Mortis & Lokomotor Mortis \\
\hline Wingardium Leviosa & Uingardium Leviosa \\
\hline Alohomora & Alohomora \\
\hline
\end{tabular}

A spell is a magical action often accompanied by an incantation, usually Latin based, that makes use of the magical force of the wizarding world in order to accomplish extraordinary feats. (http://harrypotter.wikia.com/wiki/Spell) The Latin based spells are partially preserved in TT. The translator has decided to literally translate only the root of the words and he has preserved the Latin suffixes. This is a very wise choice because the translator has made it possible to the TT reader to understand the meaning of the spells on the one hand, and has retained the Latin-oriented characteristic of a spell as well as the writer's style, on the other hand. However, as we see from the table above, the Locomotor Mortis, Wingardium Leviosa, Alohomora have been not been translated into Albanian but the terms are in italics. Their meaning can be understood by the context.

"Petra" means "stone" in Latin and "factus" means "to become". Totalus comes from Latin "totus" meaning "complete". Lumos means "light" and "drite" (light) in "Dritum" indicates that the spell is cast to "make light". Aparecium means "appear" and the translation "duku" (show up) in "Dukus" clarifies the meaning of the spell. Expelliarmus means "expel" and the Albanian word "dëboj" in "Dëbimus" refers to the same meaning. Nox/Noxtic means "night" and the root of the spell "terr" in "terrus" meaning "night" in Albanian informs the TL readers that spell is about "making the place dark". This type of explicitation is evident in almost all the spells in the Harry Potter saga. Expecto Patronum is the most famous and one of the most powerful defensive charms known to wizards against Dementors. Different from other spells, the word Patronum is not translated into Albanian. In Latin and during the Roman Age, a partonus was a protector or defender. (http://www.languagerealm.com/hplang/latin_for_spells.php) Harry Potter casts this spell to be saved by the Dementors but he is not aware of who or what creature his protector would be. Such an uncertainty is linguistically left vague by the translator.

Translation of magical creatures' names

\begin{tabular}{|l|l|}
\hline Source Text & Target Text \\
\hline Animagus & Magjikafshë (HP3) \\
\hline Dementors (HP3) & Marrorësit (HP3) \\
\hline Werewolf & Ujk i egër (HP3) \\
\hline
\end{tabular}


An Animagus is a witch or wizard who can morph himself or herself into an animal at will. It is a learned, rather than hereditary skill, unlike those of a Metamorphmagus. (http://harrypotter.wikia.com/wiki/Animagus). "Magjikafshë" in Albanian means half wizard half animal. Even though the transfiguration process is not included in the word, the meaning is rendered by the word "magji" meaning "magic", making such creatures imaginary ones. A Dementor is a non-being and Dark creature, considered one of the foulest to inhabit the world. Dementors feed upon human happiness, and thus cause depression and despair to anyone near them. (http://harrypotter.wikia.com/wiki/Dementor ) Dementor is a Latin borrowing used by Rowling to refer to these fearsome creatures. Dementor derives from the verb "dement" which means "to make mad and insane". The Albanian translation "Marrosësit" shows the same feeling conveyed in the source text, meaning "sb/sth who/which drive sb mad". Werewolf in folklore and superstition, a werewolf is a human being who has changed into a wolf, or is capable of assuming the form of a wolf, while retaining human intelligence. However, the translator makes use of the simplification technique and used a general term in Albanian "ujk i egër" which is backtranslated as "wild wolf". The magical transformation feature of the noun werewolf is lost in translation but the physical features of the wolf are retained.

Translation of cultural-bound terms related to boarding school

\begin{tabular}{|l|l|}
\hline Source Text & Target Text \\
\hline Head boy & Kryeshkollar \\
\hline Head girl & Kryeshkollare \\
\hline Prefect & Prefekt \\
\hline
\end{tabular}

A boarding school is a school where some or all pupils study and live during the school year with their fellow students and possibly teachers or principals. The word 'boarding' is used in the sense of "bed and board," i.e., lodging and meals. This kind of system is typically British and the terminology related to the boarding school presents the traslator with some difficulties. A Head Boy or Head Girl is a seventh year student who has authority over Prefects at Hogwarts School of Witchcraft and Wizardry. (http://harrypotter.wikia.com/wiki/Head_Boy) The translator has made use of the source-oriented strategy, thus being faithfull to the source text and preserving the Britishness of the boarding school, informing the source text reader about the differneces that educational systems in two countries have. A prefect at $\underline{\text { Hogwarts School of Witchcraft }}$ and Wizardry is a student who has been given extra authority and responsibilities by the Head Boy of Girl of

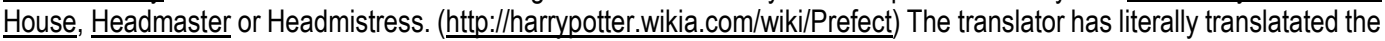
word "prefect" even though it is a false friend, considering that the word "prefekt" in Albanian has another meaning. The source oriented strategy on the part of the translator aimed at informing the TL reader about the Britishness of the boarding school.

\section{Comparative analysis of translation strategies in proper nouns}

The second group of CSIs, according to Axela, are the proper nouns. More than one hundred proper nouns can be found only in the first novel of the Harry Potter series, namely Harry Potter and the Philosopher's Stone, portraying different events, objects and phenomena in both the magical world and the real one. Several scholars have discussed whether names should be translated or not. While elaborated on Harry Potter's magical elements, Jentsch stated that "Names readily understood by the target audience and those that have no further significance can and should be left in the original. After all, English names for people and places can help create the sense of place, integral to a novel whose setting is in large part a boarding school in Britain. It is obvious that J. K. Rowling chooses her characters' names carefully. They often have a meaning, be it in French, the language and literature she studied at the University of Exeter, or otherwise. Malfoy (bad faith), Voldemort (flight from death) and Sirius (the Dog Star) are examples of this. The decision of how much should be left in the original language, and how to translate such significant words (when necessary to promote these meanings) is a subjective one, but also one that will affect the overall success of the translation". (Jentsch 2002: 285)

As we mentioned above, several scholars have studied the roles of proper nouns in children's literature and proposed alternatives and translation strategies. For the purpose of this study, strategies proposed by Eirlys E. Davies will be used as the theoretical ground of our analysis. He distinguishes seven strategies: preservation, addition, omission, globalization, localization, transformation and creation. (2003: $65-100)$

Preservation occurs when the translators can maintain the name from the ST without any changes. Next, the second group includes the names which receive a literal translation. Davies's second strategy is addition, when a translator "decide[s] to keep the original item but supplement[s] the text with whatever information is judged necessary" (Davies 2003, 
p.77). Additional information can be inserted within the text or in a footnote, gloss, introduction and notes (Aixelá cited in Davies 2003, p.77). The opposite strategy to addition is omission, when translators decide, as Davies writes, to "omit a problematic CSI altogether, so that no trace of it is found in the translation" (Davies, 2003, p.79). For example, a character may speak in a dialect in the ST, while s/he speaks a standard language in the translation. Omission can be justified, as Davies puts it, when a translator cannot convey any meaning for the CSIs in the translation. Davies argues that, when "the inclusion of a problematic culture-specific item might create a confusing or inconsistent effect," it is better to omit it (Davies, 2003, p.80). Davies's next strategy is globalization, "the process of replacing culture-specific references with the ones which are more neutral or general" (Davies 2003, p.83). An opposite strategy to globalization is what Davies calls localization, when translators "try to anchor a reference firmly in the culture of the target audience" (Davies 2003, pp.8384). Davies states that this strategy also includes phonological and grammatical adaptation of names and the use of gender endings The last Davies's strategy is called creation and means a creation of a CSI which is firmly or totally different from the ST or is not present in there (Davies, 2003, pp.72-89). This strategy is rarely used and often includes an idea of compensation; for example, a translator can omit puns or alliterations in one place and put them elsewhere.

The strategy of preservation: No orthographic adjustments occur and as such they can be considered as borrowings in the target language.

The application of preservation

\begin{tabular}{|l|l|}
\hline Source Text & Target Text \\
\hline Miranda & Miranda \\
\hline Doris & Doris \\
\hline Hagrid & Hagrid \\
\hline Oliver & Oliver \\
\hline
\end{tabular}

From the examples in the table we notice that the names that have been preserved are not motivated names and it is safe to preserve them and respect the cultural setting of the source test. Furthermore, even though they are not very frequent names in Albanian, they do not sound exotic to the target text reader due to the phonological features.

The application of transcription strategy proposed by Fernandes implies the adaption of phonological and grammatical conventions of the target language:

The application of localization - (phonologic adaption)

\begin{tabular}{|l|l|}
\hline Source text & Target text \\
\hline George & Xhorxhi \\
\hline Charles & Çarli \\
\hline Ginny & Xhini \\
\hline Sirius Black & Sirius Blek \\
\hline
\end{tabular}

From the examples in table 2 we can say that the origin of the name is maintained and they are transferred into the target text as they are pronounced in the source language. Most of them are not semantically loaded names, however, the name Sirius Black has lost its connotation in translation. The surname Black is descriptive of the character and the source text reader can interpret the word "black" in two ways: black as a color related to evil (he was thought to be a very negative character throughout the book until the opposite was proved), or black can be related to the dark period that he went through in prison even though he was innocent. Such implications are not experienced by Albanian readers.

The application of substitution

\begin{tabular}{|l|l|}
\hline Source Text & Target Text \\
\hline Leaky Cauldron & Kusia Magjike \\
\hline Argus & Laraska \\
\hline Wood & Bastuni \\
\hline
\end{tabular}


Leaky Cauldron is one of the shops in the imaginary world of wizards. It is translated as Kusia Magjike, meaning Magic Cauldron. Although "leaky" and "magic" are semantically two different words we think that the change of words is a right decision because it is directly descriptive of the fictional worlds. The name Argus comes from Greek mythology referring to a giant with 100 eyes who was made guardian. It also has a second meaning referring to a large bird of the Maley Peninsula. http://www.thefreedictionary.com/Argus/bird In Albanian it is translated as Laraska meaning magpie. Laraska in Albanian is metaphorically used to refer to a person who sneaks around. This substitution is very descriptive of the character Argus, whose role in the novel is to guard and report any problems. "Wood" is a general term whereas "Bastun" in target language is an object made of wood, meaning "walking stick". We believe that the meaning is maintained despite this change.

Recreation is the strategy which involves the recreation of an invented name in the ST text into the Target text, thus trying to reproduce similar effects of this newly-created referent in another target cultural setting.

\begin{tabular}{|l|l|}
\hline Source Text & Target Text \\
\hline Quaffle & Pluf \\
\hline Hufflepuff & Baldoskuqi \\
\hline Mcgonagall & MakGur \\
\hline Dedalus Diggle & Dedalus Luks \\
\hline
\end{tabular}

Recreation is different from substitution in that, the latter makes use of the target text lexicon whereas recreation is depended on the translator's inventive abilities to coin a new word which is as alien in meaning as it is in the source text but which can be adjusted to the target language phonological system, thus be readable and easy to remember. Quaffle Pluf are invented words, the latter sounding more natural in Albanian.

Deletion is a translation procedure which involves removing a source text name or part of it in the target text.

The application of the strategy of deletion:

\begin{tabular}{|l|l|}
\hline Source Text & Target Text \\
\hline Severus Snape & Pitoni \\
\hline
\end{tabular}

Severus is a Latin word meaning "severe, harsh" and Snape rhymes with "snake". http://latindictionary.wikidot.com/adjective:severus The translator has merged the mane and the surname into one: Piton which refers to a breed of snake: python. Although the word Severus is rarely used, the message is conveyed.

\section{Literal translation of nicknames}

\begin{tabular}{|l|l|}
\hline Source Text & Target Text \\
\hline Nearly-Headless Nick & Niku Gati-Pa-Kokë \\
\hline You-Know - Who & Ti-Edi-Kushi \\
\hline Moony & Hënori \\
\hline Wormtail & Bishtnxehti \\
\hline Grim & Mjerani \\
\hline Dementors & Marrosësit \\
\hline Bludgers & Fluturakët \\
\hline Baruffio & Kacafyti \\
\hline
\end{tabular}

The examples mentioned in the table 4 are expressive or descriptive names and the only strategy possible is to translate them literally so that the reader understands their descriptive role or, as in the case of "Nearly Headless Nick", the comic effect as well even though the alliteration N-N is not preserved. Bludgers are balls used in the fictional game of Quidditch and it is an invented word. However, the translator used a standard word from target language lexis to make it more understandable for readers. Additionally, the translator has preserved the author's style by capitalizing it despite the fact that objects are not capitalized in Albanian. Dementor is a Latin word meaning "fearsome creature" [8]. Even though the 
word "dementor" is capitalized, it is in plural referring to a group of creatures having the same characteristic. The Albanian translation "Marrosësit" shows the same feeling that is conveyed in the source text.

Apart from the above mentioned, mixture of strategies occurs when the proper noun is a compound noun consisting of a meaningful noun and a neologism. Such names are typical of the fantasy literature as they are alien to the readership just as the world of fantasy is.

\begin{tabular}{|l|l|}
\hline Source Text & Target Text \\
\hline Voldemort & Fluronvdekja \\
\hline Albus Dumbledore & Albus Urtmori \\
\hline
\end{tabular}

Voldemort comes from French "vol de mort" and it can be interpreted as "flight of death". In the target language we have the translation "Fluronvdekja". http://scifi.stackexchange.com/questions/3218/etymology-of-the-name-voldemort The word Vol is translated as "Fluron" unfinished word of "fluturon", whereas "mort" is literally translated as "vdekja". Here the translator is mixing the strategy of recreation with that of rendition.

Albus is a Latin word, meaning "white" and Dumbledore is an old English word that in Old English meant "bumblebee". http://www.answers.com/Q/What_does_Albus_Dumbledore\%27s_name_mean_in_latin The name Albus has remained unchained in the target language. Albus sounds very typical name of a magician and very referential to the magical world, thus, it being substituted with a more frequently-heard name would lose its mysticism. The first part of the surname Dombledore, "dumble" rhymes with "humble", meaning a "modest in behavior, attitude and spirit" http://www.thefreedictionary.com/humble The surname in the target language is Urtmore, "I urtë", according to the Albanian Language Dictionary, means "a quiet and mature person".

\section{Conclusions}

As we see from the discussion and the comparative analysis above, it is obvious that the translation of children's literature is not as simple as it might seem. Underlying meanings and connotations are rules rather than exceptions. Proper nouns can be considered as CSI-s which should not be underestimated because they are demonstrative elements of characters, their personality, origin, their magical traits and most importantly they indicated J.K. Rowling writing style and her ability to coin exotic names as well as relate them to myths, Latin or French language. The presence of so many alien terms and the complexity of their phonological sequences might cause barriers to the child reader. On the other hand, oversimplification would fade the fantasy elements that the books offer. In the children's fantasy literature, proper nouns must convey the elements of the unusual, but they must be acceptable and easy-to-read-and-remember.

The application of various strategies in the Albanian translation of CSI in the first three HP novels account for the complexity of the proper nouns. There is a tendency on the part of the translator to preserve and respect the source text culture, when possible. Conventional names are mostly transcribed; some of them have been copied serving as a reference to the British setting. Loaded names have been literally translated but there are cases when the translator left them unchanged, keeping the child reader uninformed about the character's personality.

We can say that names with reference to Latin, French or mythology can partially be perceived as descriptive names from the source text readers. In Albanian, the translator resorted to the method of translation proper to make them understandable to the target text readership. However, this strategy resulted in translation loss of one of the most important J.K. Rowling's stylistic aspects: Latin-rooted words. Generally the equivalent effect has been achieved regarding CSI-s as a result of the translator's encyclopedic knowledge.

\section{Bibliography}

[1] Akademia e Shkencave e Shqiperisë: Fjalor i Gjuhës Shqipe, Tiranë, 2006.

[2] Axela, Javier Franco. "Culture-specific Items in Translation", in R. Alvares and M. C.-A Vidal Translation Power Subvention, Vol. 8, 52-78, Clevedon: Multilingual Matters. 1996. 
[3] Davies, E. E. A Goblin or a Dirty Nose? The Translator: Studies in Intercultural Communication, 9 (1), pp.65100. 2003.

[4] Jentsch, N.K. Harry Potter and the Tower of Babel: Translating the Magic. Në Lana, A. White. The Ivory Tower and Harry Potter: Perspectives on a Literary Phenomenon. Colombia, Missiuri Univeristy of Missiury Press. 2002.

[5] Gates, Pamela S, Susan B Steffel, and Francis J Molson. Fantasy Literature for Children and Young Adults. Lanham: The Scarecrow Press, 2003.

[6] Puurtinen, T. 'Syntax, readability and ideology in children's literature', Meta 43(4). 1998.

[7] Rudvin, M. \& Orlati, F. Dual Readership and Hidden Subtexts in Children"s Literature: The Case of Salman Rushdie"s Haroun and the Sea of Stories", in: van Coillie, Jan and Walter P. Verschueren (eds.), Children's literature in translation. Challenges and strategies, Manchester: St. Jerome Publishing, pp. 157-184. 2006.

[8] Oittinen, R. I am me - I am other: On the Dialogics of Translation for Children Vammalan, Kirjapaino Oy: University of Tampare. 1993.

[9] Klingberg, G. Facets of Children's Literature Research: Collected and Revised Writings.

[10] Svenska barnboksinstitutet, Stokholm. 2008

[11] Newmark, Peter. A Textbook of translation. New York, London, Toronto, Sydney, Tokyo. Prentice Hall. 1988.

[12] Shavit, Z. Poetics of Children's Literature, Athens and London, University of Georgia Press. 1986.

[13] On line sources:

[14] http://www.languagerealm.com/hplang/latin_for_spells.php

[15] http://harrypotter.wikia.com/wiki/Spell

[16] http://www.languagerealm.com/hplang/latin_for_spells.php

[17] http://harrypotter.wikia.com/wiki/Animagus

[18] http://harrypotter.wikia.com/wiki/Dementor

[19] http://harrypotter.wikia.com/wiki/Head_Boy

[20] http://harrypotter.wikia.com/wiki/Prefect

[21] http://www.thefreedictionary.com/Argus/bird

[22] http://latindictionary.wikidot.com/adjective:severus

[23] http://scifi.stackexchange.com/questions/3218/etymology-of-the-name-voldemort

[24] http://www.answers.com/Q/What_does_Albus_Dumbledore\%27s_name_mean_in_latin

[25] http://www.thefreedictionary.com/humble 